\title{
Fabrication of AIN Coatings by Reactive Atmospheric Plasma Spray Nitriding of Al Powders
}

\author{
Mohammed Shahien*, Motohiro Yamada, Toshiaki Yasui and Masahiro Fukumoto \\ Department of Production Systems Engineering, Toyohashi University of Technology, Toyohashi 441-8580, Japan
}

Atmospheric Plasma Spray (APS) is well-established process and is widely used to produce various coatings with high deposition rate for structural and functional applications. Aluminum nitride is a promising material due to its outstanding properties. In this study, AlN coatings were synthesized by APS process through reactive plasma nitriding of Al powders by nitrogen plasma. Al powders were supplied into the plasma stream by Ar carrier gas and reacted with the surrounding plasma, then were deposited onto substrate. The obtained coatings were cubic-AlN/Al mixture with $100 \mu \mathrm{m}$ of thickness at $150 \mathrm{~mm}$ of spray distance. Since the nitride content increases gradually with spray distance, the coating almost consists of AlN at $300 \mathrm{~mm}$. However, the thickness of the coatings decreased with increasing spray distance, it was less than $10 \mu \mathrm{m}$ at $300 \mathrm{~mm}$ spray distance. The nitriding reaction was investigated and it indicated that Al particles may react during flight and after deposition on the substrate surface. Completing the nitriding during flight (formation of AlN in-flight) decreases the coatings thickness. We can conclude that enhancing the nitriding reaction after deposition at short spray distance may enable to fabricate thick AlN based coatings. [doi:10.2320/matertrans.T-M2010804]

(Received November 9, 2009; Accepted January 6, 2010; Published March 25, 2010)

Keywords: atmospheric plasma spray, reactive nitriding, cubic aluminum nitride, spray distance

\section{Introduction}

Aluminum Nitride (AlN) is an attractive material due to its outstanding electrical and mechanical properties: high thermal conductivity (up to $320 \mathrm{~W} / \mathrm{mK}$ for pure single crystal and $180-220 \mathrm{~W} / \mathrm{mK}$ hot pressed material), good chemical/physical stability at fairy high temperature regions, high hardness (Hv 1400), high electrical resistivity $\left(10^{13} \Omega \mathrm{cm}\right.$ ), low thermal expansion coefficient (similar to silicon and GaAs) and high resistance of molten metals, wear and corrosion. ${ }^{1-4)}$ Therefore, AlN has been expected to contribute several applications such as heat sinks, electronic substrates, semiconductor packages, crucibles and vessels for handling corrosive chemicals and molten metals, parts of semiconductor equipment and reaction vessels of etching. Usually vacuum vapor phase deposition techniques like chemical vapor deposition (CVD) and physical vapor deposition (PVD) have been used for fabricating AlN films. However, fabrications by these processes are limited to AlN thin films due to its low deposition rates. In order to use AlN for a protection layer, thick coating (about $100 \mathrm{~mm}$ of thickness) is required.

Thermal spray process is able to fabricate thick coatings easily due to its high deposition rates (several $\mu \mathrm{m} / \mathrm{min}$ or more). Deposition mechanism in thermal spray process depends on molten or semi-molten particles for coatings formations. It was reported that fabrication of thermal sprayed AlN coatings will enable cost-effective solutions for a number of applications. ${ }^{5)}$ However, it is difficult to fabricate AlN coatings by conventional thermal spray processes directly from AlN powder due to the thermal decomposition of AlN during spraying.

In order to fabricate AIN coatings by plasma spray, plasma nitriding of aluminum powders was considered. Pure aluminum powder can react with surrounding active species in

*Graduate Student, Toyohashi University of Technology plasma such as nitrogen ion or atom. There are some studies about nitriding reaction of aluminum particles. ${ }^{6,7)}$ However, it did not aim to fabricate AlN coatings. In our previous studies, ${ }^{8,9)}$ it was possible to fabricate AlN based coatings by radio frequency (RF) plasma spraying through plasma nitriding of $\mathrm{Al}$ powders. However it was difficult to obtain dense AlN coatings by RF plasma spray system due to its low particle velocity. ${ }^{10)}$ Furthermore, the RF plasma spray was carried out in vacuum ambient.

The possibility of fabrication of AlN coatings by Atmospheric DC Plasma Spray (APS) system, through the nitriding reaction between aluminum feedstock powders and the surrounding nitrogen plasma was investigated in this study. APS is an atmospheric process and characterized by its high deposition rate, high particle velocity, ${ }^{10)}$ moreover it enables to use $\mathrm{N}_{2}$ as plasma gas and become plasma nitriding technique. In order to control the process, the influence of spray distance on the nitriding reaction of $\mathrm{Al}$ powders was investigated. Furthermore, the plasma nitriding reaction of aluminum particles was investigated during flight and after deposition on the substrate.

\section{Experimental Procedure}

Pure aluminum powder (Toyo Aluminium K. K., Japan) with an average particle size of $30 \mu \mathrm{m}$ was used as feedstock powder. The morphology of the powders as shown in Fig. 1, the particles are quasi-spherical in shape.

All experiments were carried out by atmospheric DC plasma spray system (APS: 9MB, Sulzer Metco) as illustrated in Fig. 2, using primary gas of $\mathrm{N}_{2}$ and secondary gas of $\mathrm{H}_{2}$. Table 1 indicates the typical spraying parameters in APS system. The feedstock powders were supplied to the plasma stream with carrier gas of Ar. Blasted soft steel (SS400) plates were prepared as substrate. The spray distance was changed from 100 to $300 \mathrm{~mm}$. The Nitriding reaction of $\mathrm{Al}$ particles during flight in the plasma was investigated by 


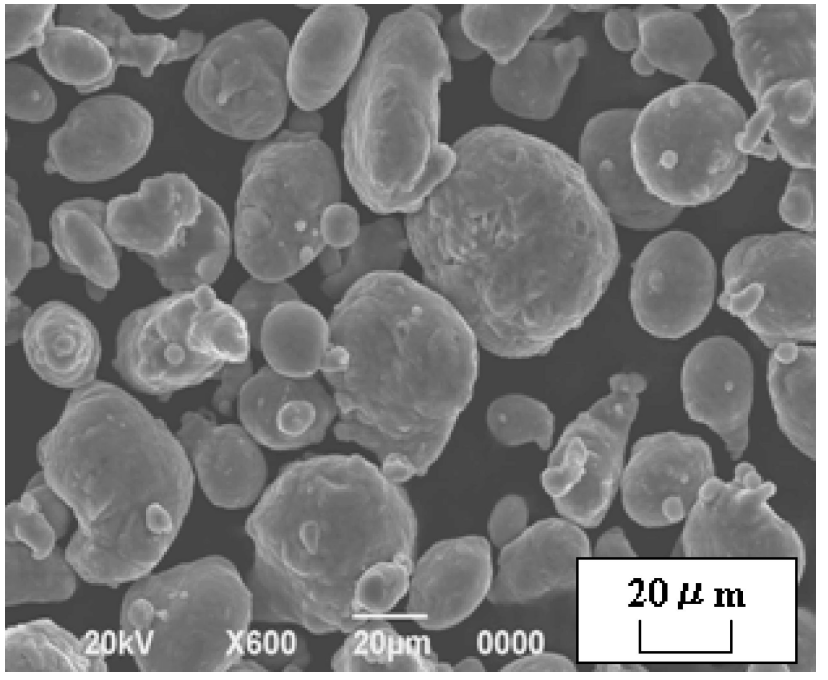

Fig. 1 Morphology of Aluminum powders.

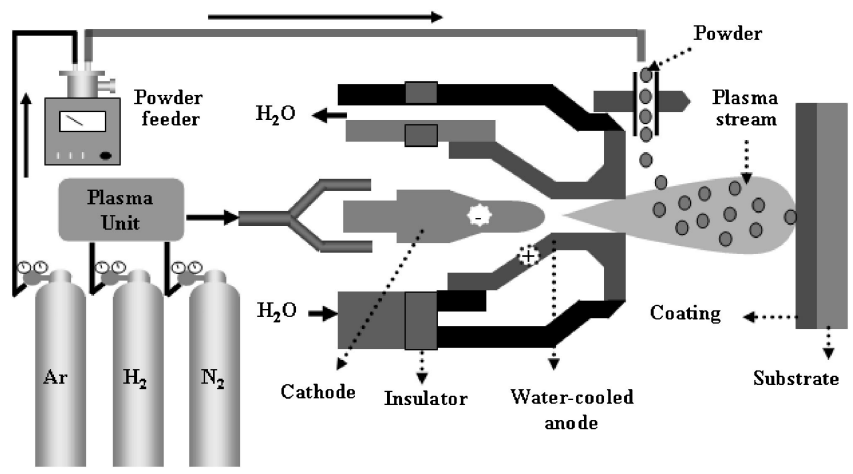

Fig. 2 Schematic diagram of APS system.

Table 1 Typical spray conditions.

\begin{tabular}{cc}
\hline 1st gas: Pressure & $\mathrm{N}_{2}: 330.9 \mathrm{kPa}$ \\
: Flow rate $(1 / \mathrm{min})$ & $: 100$ \\
\hline 2nd gas: Pressure & $\mathrm{H}_{2}: 344.7 \mathrm{KPa}$ \\
$:$ Flow rate $(1 / \mathrm{min})$ & $: 5$ \\
\hline Spray distance $(\mathrm{mm})$ & $100-300$ \\
\hline Carrier gas: & $\mathrm{Ar}$ \\
flow rate $(1 / \mathrm{min}):$ & 1 \\
\hline Substrate materials & $\mathrm{SS} 400$ \\
\hline
\end{tabular}

particle collection on carbon tape without using substrate. Nitriding reaction on the substrate was examined by irradiation of $\mathrm{N}_{2}$ plasma to Al substrate. Substrate temperature was measured on the back surface of the substrate by thermocouple. The existence of AlN phase in the deposited coatings and the collected particles were verified by X-ray diffraction analysis (XRD: RINT-2500, Rigaku), with $\mathrm{CuK} \alpha$ radiation. Cross section microstructures of the coatings and the collected particles were observed by scanning electron microscope (SEM: JSM-6390, JEOL). The hardness of the coatings was examined by micro Vickers hardness tester (HMV-1, SHIMADZU).

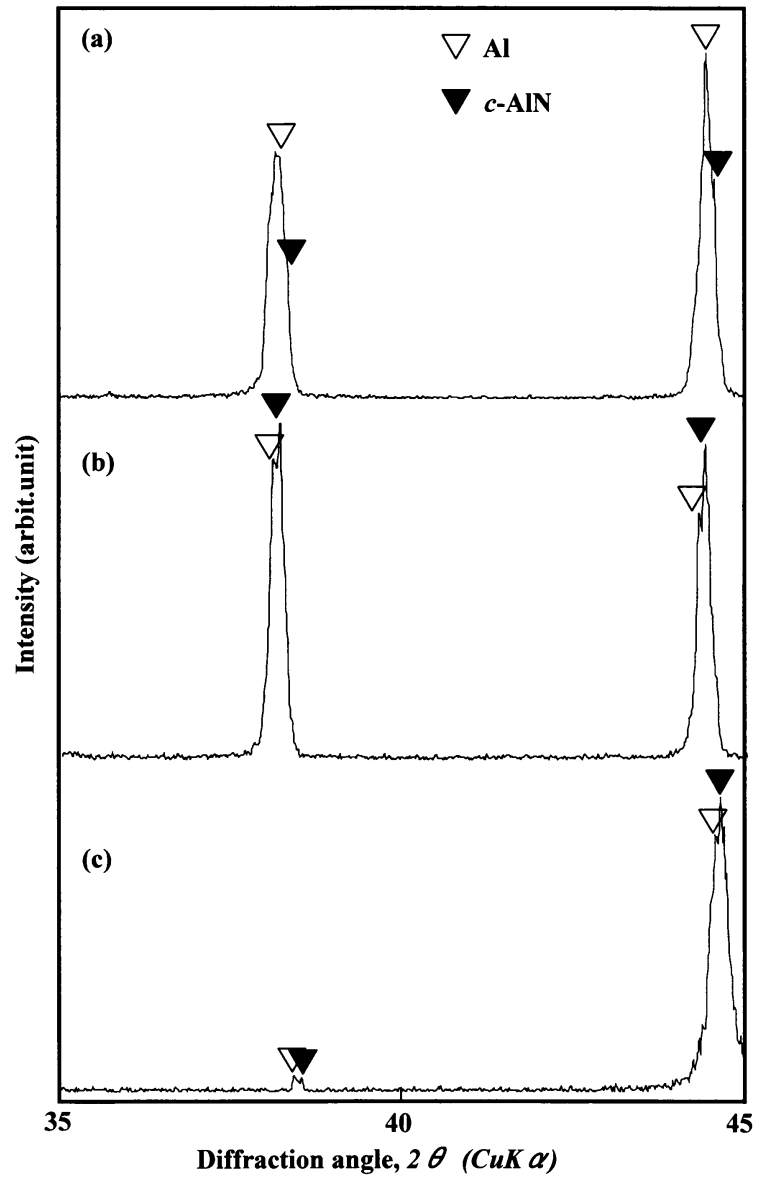

Fig. 3 XRD spectra of the fabricated coatings at spray distance of (a) $150 \mathrm{~mm}$, (b) $200 \mathrm{~mm}$ and (c) $300 \mathrm{~mm}$.

\section{Results and Discussion}

\subsection{Influence of spray distance}

XRD spectra of the fabricated coatings at different spray distance are shown in Fig. 3. It indicates that the fabricated coatings consist of cubic-AlN/Al composite. Furthermore, the concentration of the nitride phase in the coatings enhanced with increasing the spray distance. At $300 \mathrm{~mm}$ spray distance, $c$-AlN based coating was fabricated as shown in Fig. 3(c). Formation of $c$-AlN phase was identified from the intensity of the strongest peak, that the main peak of Al lies around $2 \theta$ value of $38^{\circ}$ and for $c$-AlN the main peak lies around $44^{\circ}$ of $2 \theta$ value. Therefore it became clear that fabrication of $c$-AlN based coating is possible in APS system through the reaction between $\mathrm{Al}$ feedstock powder and $\mathrm{N}_{2}$ / $\mathrm{H}_{2}$ plasma.

It is well known that AIN has a hexagonal and a cubic structure. The hexagonal AlN is more common and stable at ambient conditions. Generally, direct nitriding of $\mathrm{Al}$ powders forms AlN with a hexagonal structure. It is considered that the formation of $c$-AIN phase in the coatings is related to the rapid cooling and solidification of sprayed particles at the collision to the substrate surface. As it is well known that in plasma spray process the powder particles are quickly melt in the plasma stream and accelerated to the substrate where they spread upon impact and rapidly solidify. ${ }^{11-15)}$ 

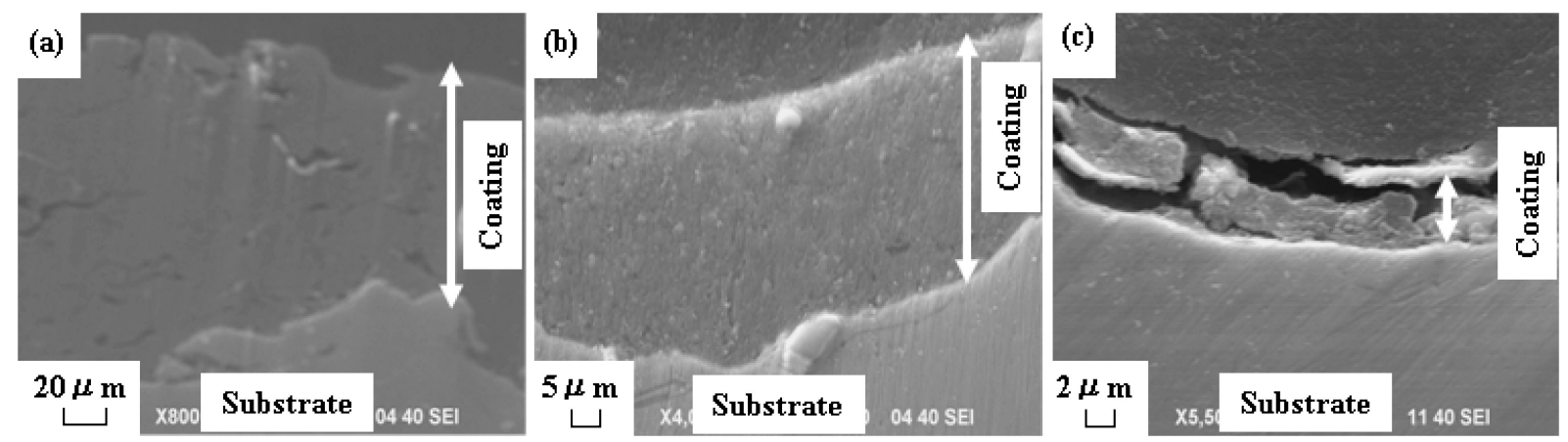

Fig. 4 SEM cross sections of the fabricated coatings at spray distance of (a) $150 \mathrm{~mm}$, (b) $200 \mathrm{~mm}$ and (c) $300 \mathrm{~mm}$.

Rapid solidification is a relatively recent development in which a two-phase mixture of equilibrium phases in a eutectic alloy could be replaced by an extended solid solution like non-stable phases, a new crystalline phase, or a noncrystalline phase (i.e. metallic glass) simply by quenching with enough rapidity from the liquid state. ${ }^{16-20)}$ Therefore in APS process the sprayed particles experience very rapid cooling rates upon impact with the substrate which prevent the complete crystal growth and formation of the stable hexagonal AlN phase. Moreover, the high particle velocity in this process does not provide enough time for complete crystal growth before impacting on the substrate and rapid cooled, which assist the formation of $c$-AlN phase instead of hexagonal phase.

Regarding the oxidation of $\mathrm{Al}$ particles during spraying, our assumption to prevent the oxidation depends on keeping the $\mathrm{Al}$ particles in the centre of the plasma stream (where there is no oxygen) by using low carrier gas flow rate of $11 /$ min. Which was enough to supply the Al powders to the beginning of plasma stream, then the particles were simultaneously accelerated by the plasma stream and gain their velocity and temperature by thermal and kinetic transfers towards the substrate.

Moreover, the oxygen content (from the oxide layer on the surface of $\mathrm{Al}$ particles or even if some air oxygen contaminated) will interact with the surrounding $\mathrm{N}_{2}$ plasma and form aluminum oxide nitride phase (AlON). Then AlON phase interact with the surrounding $\mathrm{N}_{2} / \mathrm{H}_{2}$ plasma to form $c$ AlN which is reported by J. C. Kuang et al. ${ }^{21)}$ They reported that, nitriding of AlON form $c$-AlN phase, because both $\mathrm{AlON}$ and $c$-AlN phase have the same cubic symmetry. The crystal structure of $c$-AlN is cubic and closely packed, and the non-metal arrangement in $\mathrm{AlON}$ is also cubic and closely packed. This part needs more clarifications, however, these reactions can be considered in this process.

Cross section microstructures of the coatings fabricated with different spray distance are shown in Fig. 4. The thickness of the coating fabricated at $150 \mathrm{~mm}$ spray distance was approximately $100 \mu \mathrm{m}$. The hardness of the coating was $540 \mathrm{Hv}$ which is much higher than Al. Therefore it emphasizes the nitriding reaction and formation of AlN phase in the fabricated coating i.e. AlN phase in the coating increased its hardness.

However, the thickness of the coatings decreased with increasing the spray distance as shown in Fig. 4(b) and (c). The coatings thickness suppressed due to decreasing the

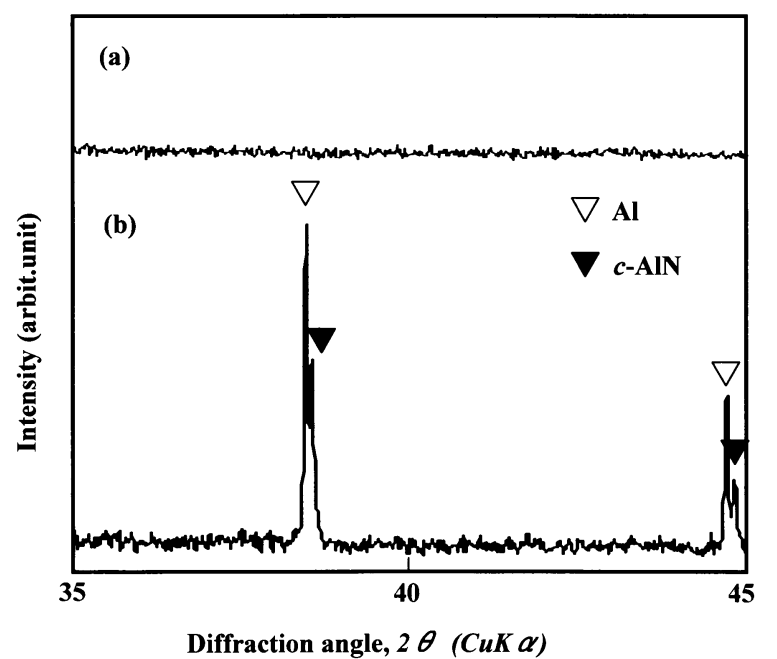

Fig. 5 XRD spectra of (a) carbon tape and (b) collected particles on the carbon tape.

particles temperature with increasing spray distance which lead to reducing the deposition efficiency of the particles. Also, with increasing spray distance some sprayed particles deviated from substrate. Moreover, complete nitriding of some Al particles (and formation of AlN particles) during flight with increasing spray distance prevents its deposition the formed AlN particles during plasma cannot deposit because it doesn't have a molten phase which is required for deposition in thermal spray process. Therefore, though it was possible to fabricate thick $c$-AlN/Al composite coating by APS and with increasing the spray distance the nitride content was enhanced, the coating thickness was suppressed. In other words it was difficult to obtain thick AlN based coatings under these conditions. In order to fabricate thick AIN coatings in APS process further information about the nitriding phenomena of $\mathrm{Al}$ particles is required. Therefore, the nitriding reaction of $\mathrm{Al}$ particles was investigated during flight and after deposition on the substrate in the following sections.

\subsection{Nitriding reaction during flight}

The reaction during flight was investigated by XRD analysis for the collected powders on carbon tape. XRD spectra of the carbon tape before and after collecting the sprayed particles are shown in Fig. 5. It indicates that some of $\mathrm{Al}$ particles reacted with the surrounding $\mathrm{N}_{2}$ plasma during 

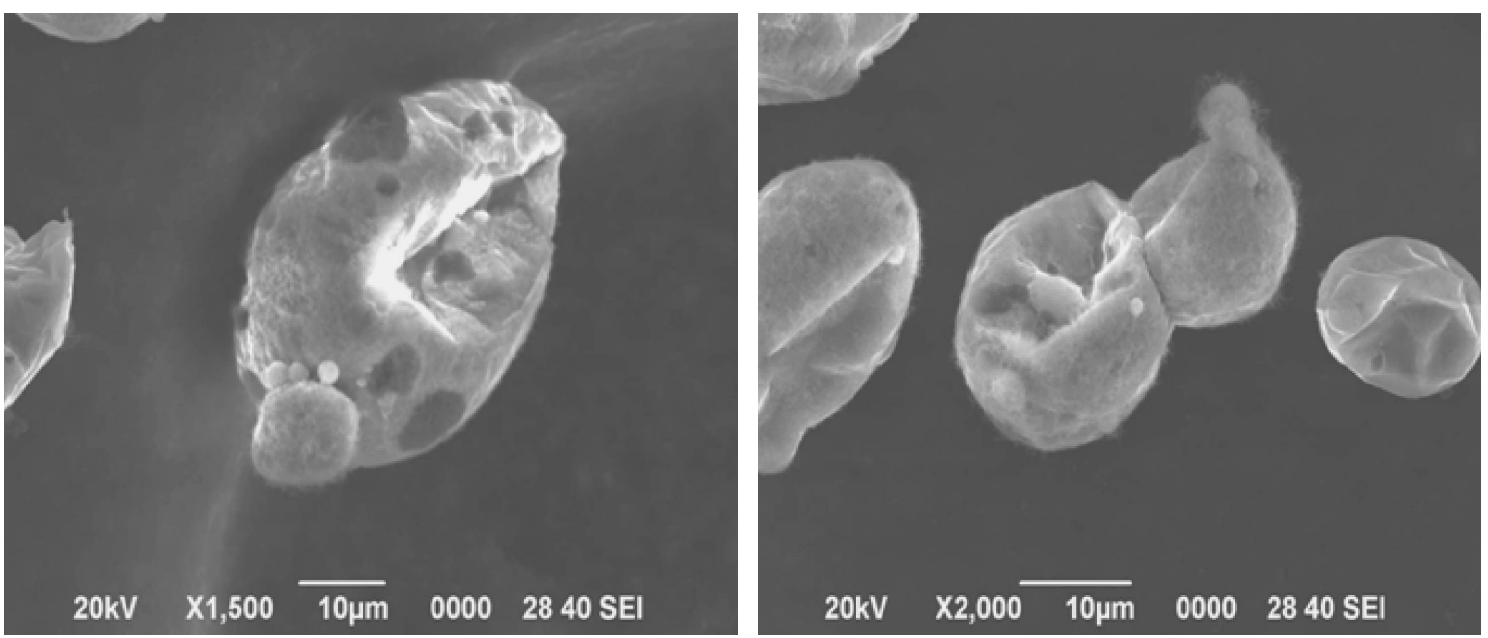

Fig. 6 SEM morphology of the collected particles on carbon tape showing the AlN egg-shell structure of the reacted particles.

flight (Fig. 5(b)). The morphology of some collected particles is shown in Fig. 6. It is clear that the collected particles have an egg-shell structure which is considered to be a typical feature for formation of $\mathrm{AlN}$ through direct nitriding of $\mathrm{Al}$ particles. ${ }^{8,22-24)}$ The egg-shell structure was formed via three steps as shown below.

(1) Nitriding at the surface of the particles with the formation of a crystalline nitride shell. Due to the thermal stress of large volume of the molten $\mathrm{Al}$, the $\mathrm{Al}$ starts to break the AlN shell to go out. Moreover at this high temperature conditions, the generation rate of the reaction heat is enough to vaporize the molten $\mathrm{Al}$ present inside the shell which is the beginning of the second step.

(2) The inner molten $\mathrm{Al}$ expands much enough to break the AlN shell and flow out as molten or vaporized Al core by capillary-like phenomena.

(3) The diffused Al vapor reacted with the surrounding $\mathrm{N}_{2}$ through volume nitridind outside the shell with a remaining hole or an empty core as it is clear in Fig. 6.

Therefore XRD spectra and the egg-shell structure which appeared in some of the collected particles emphasize the nitriding reaction of some Al particles during flight in APS process.

\subsection{Nitriding reaction after deposition}

Nitriding reaction after deposition was investigated by irradiation of $\mathrm{N}_{2} / \mathrm{H}_{2}$ plasma to $\mathrm{Al}$ substrate without using powders. Figure 7 shows the XRD spectra of the Al substrate before and after $\mathrm{N}_{2} / \mathrm{H}_{2}$ plasma irradiation. It indicates that the cubic AlN phase formed on the irradiated Al substrate as shown in Fig. 7(b). Therefore, during APS process using Al powders, some Al particles reacted after deposition on the substrate. To understand the reaction after deposition, the substrate temperature was measured from the back side at different spray distance as shown in Fig. 8. It was clear that at short spray distance $(100 \sim 150 \mathrm{~mm})$ the substrate is directly touched by the plasma jet. Therefore, the temperature is enough to melt or semi-melt $\mathrm{Al}$ particles to react with $\mathrm{N}_{2}$ plasma. However with increasing the distance the plasma jet does not touch the substrate and the temperature is not enough for the reaction.

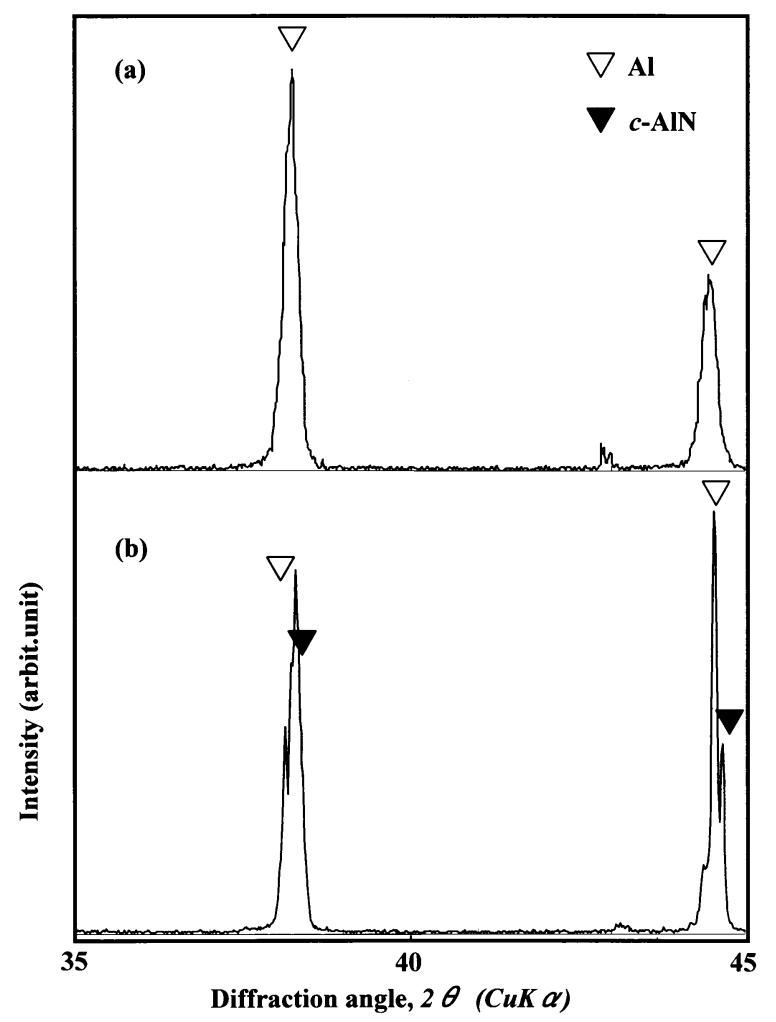

Fig. 7 XRD spectra of the Al substrate (a) before plasma irradiation and (b) after $\mathrm{N}_{2} / \mathrm{H}_{2}$ plasma irradiation at $150 \mathrm{~mm}$.

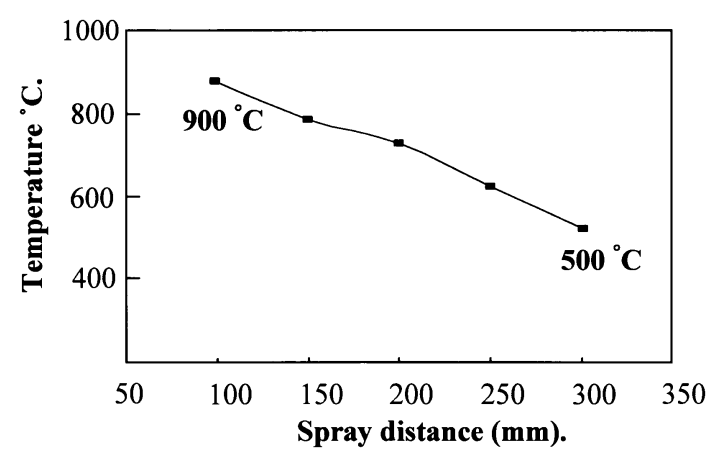

Fig. 8 Substrate temperature back side measurement. 
The formation of $c$-AlN phase during the irradiation treatment by $\mathrm{N}_{2} / \mathrm{H}_{2}$ plasma may be is related to the formation of AlON phase due to the interaction between $\mathrm{N}_{2} / \mathrm{H}_{2}$ plasma and the $\mathrm{Al}_{2} \mathrm{O}_{3}$ layer on the $\mathrm{Al}$ substrate surface. It is same as the case of $\mathrm{Al}$ particles.

Therefore, nitriding reaction of Al particles in APS occurs both during flight and after deposition on the substrate, and controlling spray distance is the key factor for controlling the nitriding reaction of $\mathrm{Al}$ powder in APS system:

(1) The nitride content increased with the spray distance due to increasing the flight time of $\mathrm{Al}$ particles in the plasma, which provides longer time for the particles to react with $\mathrm{N}_{2}$ plasma.

(2) On the other hand, with increasing spray distance the sprayed particles deviated from the substrate, and the particles temperature decreased which reduced its deposition efficiency and suppressed the coating thickness. It was also considered that the particles which completely reacted during flight could not deposit on the substrate, thus molten or semimolten particles are required for particles deposition in thermal spray process.

In order to fabricate AlN coating by reactive APS technique controlling the nitriding reaction of $\mathrm{Al}$ powder is very important. That the nitriding reaction of $\mathrm{Al}$ particle can start during flight and after deposition. However if the reaction completed during flight, the AlN ceramic particles will never deposit on the substrate.

Hereby, it is possible to fabricate $c$-AlN based coatings by APS system, thus some of $\mathrm{Al}$ particles started the reaction during flight and others started after deposition on the substrate by $\mathrm{N}_{2}$ plasma irradiation. Then the partially reacted Al particles (molten or semi-molten phase) deposited on the substrate will complete the reaction through $\mathrm{N}_{2}$ plasma irradiation and rapidly cooled and solidify on the substrate to fabricate cubic AlN structure.

Therefore, it is possible to fabricate $c$-AlN composite coatings by APS process through reactive plasma nitriding of $\mathrm{Al}$ powders. In order to fabricate thick AlN based coatings in APS process, decreasing the flight time (i.e. short spray distance) and enhancing the nitriding reaction of $\mathrm{Al}$ particles after deposition on the substrate surface considered to be promising method.

\section{Conclusions}

Aluminium nitride based coatings were fabricated by atmospheric plasma spray process through reactive plasma nitriding of $\mathrm{Al}$ feedstock powder by $\mathrm{N}_{2} / \mathrm{H}_{2}$ plasma. The following results were obtained in this study:

(1) Thick cubic AlN based coating was fabricated by APS system, and cubic phase formed due to rapid solidification of the particles during impact with the substrate.

(2) The nitride content in the fabricated coatings was promoted by increasing the spray distance, through enhancing the nitriding reaction of $\mathrm{Al}$ particles during flight.
(3) The coatings thickness suppressed with spray distance due to decreasing the particles temperature and completing nitriding of some particles during flight.

(4) Spraying of $\mathrm{Al}$ particles at short spray distance and enhancing the nitriding after deposition is useful to fabricate thick AlN based coatings in APS process.

\section{Acknowledgement}

This work was supported by MEXT KAKENHI (21760583). The authors would like to thank Toyo Aluminum K.K. for the provision of $\mathrm{Al}$ powders.

\section{REFERENCES}

1) H. O. Pierson: Handbook of Refractory Carbides and Nitrides, (Noyes Publications, New Jersey, USA, 1996) pp. 237-239.

2) A. W. Wemer: Carbide, Nitride and Boride Materials Synthesis and Processing, (Chapman \& Hall, London, 1997) pp. 6-68.

3) S. Gredelj, A. R. Gerson, S. Kumar and N. S. McIntyre: Appl. Surf. Sci. 199 (2002) 234-247.

4) E. I. Meletis and S. Yan: J. Vac. Sci. Technol. A 9 (1991) 2279-2284.

5) L. R. Krishna, D. Sen, Y. S. Rao, G. V. N. Rao and G. Sundararajan: J. Mater. Res. 17 (2002) 2514-2523.

6) Y. Tsunekawa, M. Okumiya, M. Okuda and M. Fukumoto: Proc. 11th Int. Conf. on Surface Modification Technologies, (Paris, France, 1997) pp. 234-245.

7) Y. Tsunekawa, M. Hiromura and M. Okumiya: J. Therm. Spray Technol. 9 (2000) 83-89.

8) M. Yamada, H. Nakamura, T. Yasui, M. Fukumoto and K. Takahashi: Mater. Trans. 47 (2006) 1671-1676.

9) M. Yamada, T. Yasui, M. Fukumoto and K. Takahashi: Thin Solid Films 515 (2007) 4166-4171.

10) P. Fauchais, A. Vardelle and A. Denoirjean: Surf. Coat. Technol. 97 (1997) 66-78.

11) S. Sampath, X. Y. Jiang, J. Matejicek, A. C. Leger and A. Vardelle: Mater. Sci. Eng. A 272 (1999) 181-188.

12) T. Chraska and A. H. King: Thin Solid Films 397 (2001) 30-39.

13) S. Sampath and X. Jiang: Mater. Sci. Eng. A 304-306 (2001) 144150.

14) H. Zhang, X. Y. Wang, L. L. Zheng and S. Sampath: Int. J. Heat Mass Trans. 47 (2004) 2191-2203.

15) H. R. Salimijazi, L. Pershin, T. W. Coyle, J. Mostaghimi, S. Chandra, Y. C. Lau, L. Rosenzweig and E. Moran: J. Therm. Spray Technol. 16 (2007) 291-299.

16) P. Duwez, R. H. Willen and W. Klement: J. Appl. Phys. 31 (1960) 1136-1137.

17) D. J. Tilly, J. P. A. Lofvander and C. G. Levi: Metall. Mater. Trans. 28A (1996) 1889-1900.

18) M. J. Kramer, H. Mecco, K. W. Dennis, E. Vargonova, R. W. McCallum and R. E. Napolitano: J. Non-Cryst. Solids 353 (2007) 3633-3639.

19) R. A. Rodriguez-Diaz, L. Banos, O. Novelo, C. Flores, J. Colin, J. Arenas-Alatorre and J. A. Juarez-Islas: Acta Microscopica 18 (2009) $169-173$.

20) J. Kong, Z. Ye and F. Lv: J. Alloy. Compd. 478 (2009) 202-205.

21) J. C. Kuang, C. R. Zhang, X. G. Zhou, Q. C. Liu and C. Ye: Mater. Lett. 59 (2005) 2006-2010.

22) I. Kimura, K. Ichiya, M. Ishii, N. Hotta and T. Kitamura: J. Mater. Sci. Lett. 8 (1989) 303-304.

23) T. Fujii, K. Yoshida, K. Suzuki and S. Ito: Solid State Ionics 141-142 (2001) 593-598.

24) M. Radwan and Y. Miyamoto: J. Am. Ceram. Soc. 90 (2007) 23472351. 